\title{
Usefulness of selective COX-2 inhibitors as therapeutic agents against canine mammary tumors
}

\author{
TERUYOSHI SAITO*, DAI TAMURA* and RYUJI ASANO \\ Laboratory of Veterinary Pharmacology, Nihon University College of Bioresource Sciences, Kanagawa 252-8510, Japan
}

Received November 28, 2013; Accepted January 8, 2014

DOI: $10.3892 /$ or. 2014.3010

\begin{abstract}
Cyclooxygenase-2 (COX-2) is a key enzyme for converting arachidonic acids to prostanoids, which are known to be induced during inflammation and cancer initiation. Previously, it has been reported that COX inhibitors, such as aspirin, reduce the incidence of human colorectal cancer; therefore, it is widely believed that COX-2 is a potential therapeutic and chemoprevention target for several types of human cancer. However, whether selective COX-2 inhibitors have antitumor effects against canine mammary tumor cells remains unclear. In the present study, to elucidate the antitumor effect of selective COX-2 inhibitors against canine mammary tumors, we investigated the antitumor effects of meloxicam, etodolac and celecoxib using COX-2-expressing canine mammary tumor (CF33) cells. We analyzed the effects of selective COX-2 inhibitors on COX-2 protein expression levels in CF33 cells. Celecoxib (100 $\mu \mathrm{M})$ was found to induce downregulation of COX-2 protein expression. We examined the effect of selective COX-2 inhibitors on CF33 cell proliferation. All the selective COX-2 inhibitors suppressed CF33 cell growth. Specifically, etodolac and celecoxib inhibited cell proliferation via a decrease in S-phase cells and an increase in G0/G1 arrest. We examined the apoptotic effect of selective COX-2 inhibitors on CF33 cells. Our data suggested that etodolac and celecoxib induced apoptosis in CF33 cells. In particular, celecoxib led to apoptosis mediated by the activation of the mitochondrial apoptosis pathway, including the upregulation of BAX expression, downregulation of $\mathrm{Bcl}-2$ expression and activation of caspase-3/7. Furthermore, celecoxib increased the percentages of cells in both early apoptosis and late apoptosis. Our results revealed that celecoxib induced apoptosis and cell cycle arrest in CF33 cells. The data suggested that celecoxib is the most viable candidate as a therapeutic agent for the treatment of
\end{abstract}

Correspondence to: Dr Teruyoshi Saito, Laboratory of Veterinary Pharmacology, Nihon University College of Bioresource Sciences, 1866 Kameino, Fujisawa, Kanagawa 252-8510, Japan

E-mail: saitou.teruyoshi@nihon-u.ac.jp

*Contributed equally

Key words: cyclooxygenase-2, cell proliferation, apoptosis, canine mammary tumor, celecoxib, etodolac, meloxicam canine mammary tumors. Furthermore, our findings provide the first indication that COX-2 inhibition can provide a new therapeutic strategy for treating canine mammary tumors.

\section{Introduction}

Cyclooxygenases (COXs) are catalytic enzymes that are necessary for the conversion of arachidonic acid into prostaglandin (PG) $\mathrm{G}_{2}$ and subsequently to $\mathrm{PGH}_{2}$, which is a precursor for the synthesis of prostanoids, including PGs, prostacyclins and thromboxanes. There are three COX isozymes: COX-1, COX-2 and COX-3. COX-1, which is constitutively expressed in various cell types, plays an important role in homeostatic PG synthesis. For example, COX-1-derived prostanoids contribute to platelet aggregation and cytoprotective effects in the stomach. COX-3 is a COX-1 splice variant and is expressed primarily in the brain and spinal cord; however, the detailed function of COX-3 remains unknown (1). The COX-2 isozyme is induced during inflammation, and the development of several types of cancer, such as colon, breast and prostate cancer, is closely associated with chronic inflammation (2-5). Notably, the chronic use of aspirin has been shown to reduce the incidence and progression of colorectal cancer, including familial adenomatous polyposis (6). Furthermore, breast cancer patients using aspirin exhibit a reduced risk of distant recurrence and mortality related to breast cancer (7). However, traditional non-steroidal anti-inflammatory drugs (NSAIDs) such as aspirin may produce adverse gastrointestinal effects due to the inhibition of COX-1. Newer selective COX-2 inhibitors, such as celecoxib, which is used to ameliorate adverse gastrointestinal tract-related effects, may be useful as chemopreventive agents and anticancer drugs against various cancers due to increased COX-2-specific targeting. Therefore, COX-2 may provide a potential therapeutic target for the chemoprevention of cancer.

Canine mammary tumors have long been considered a suitable animal model for human breast cancer. Recent research has focused on the similarities and differences in the molecular alterations that occur in canine vs. human mammary tumors. Canine mammary tumors are the most common tumors in female dogs, and $\sim 50 \%$ are diagnosed as malignant tumors. Furthermore, one study reported that the mammary tumors in $58 \%$ of dogs were relapsed tumors that appeared after initial removal by a regional mastectomy (8). Clinically, mammary tumors are a prominent canine disease, and the 
establishment of a new treatment for canine mammary tumors is urgently required. Similar to the findings for human breast cancer, the elevation of COX-2 expression in canine mammary tumors, compared with benign tumors (adenoma), tends to be associated with increasing malignancy (adenocarcinoma) (9). Furthermore, COX-2 expression has been shown to be absent or weak in normal mammary gland tissue $(9,10)$. Therefore, these observations suggest the potential utility of COX-2 as a therapeutic target, which may also reduce the negative impact on normal cells.

COX-2 has attracted attention as a potential tool for chemoprevention and chemotherapy for canine mammary tumors (11). However, the antitumor effects of selective COX-2 inhibitors against canine mammary tumor cells are essentially unknown. Therefore, the objective of the present study was to determine the antitumor effect of selective COX-2 inhibitors in canine mammary tumor cells. Furthermore, using canine mammary tumor cells, we compared the antitumor-effect intensity of three selective COX-2 inhibitors: celecoxib, etodolac and meloxicam.

\section{Materials and methods}

COX inhibitors. To evaluate the antitumor effect of selective COX-2 inhibitors against canine mammary tumor cell lines, we used COX-2-selective NSAIDs (celecoxib, etodolac and meloxicam). Celecoxib and etodolac were purchased from Sigma Aldrich (Tokyo, Japan). Meloxicam was purchased from Wako Pure Chemicals Ltd. (Osaka, Japan). The stock solutions of the COX-2-selective inhibitors were dissolved in DMSO. The final concentration of DMSO in the culture medium was adjusted to $0.1 \%$ in all the experiments. The control cells were treated with $0.1 \%$ DMSO. The term 'parent cells' was used to refer to non-treated cells.

Cell culture. Canine mammary tumor (CF33) cells were purchased from the American Type Culture Collection (ATCC; Manassas, VA, USA). The cells were cultured as previously described $(12,13)$. AZACB cells were purchased from Primary Cell Co., Ltd. (Hokkaido, Japan). The AZACB cells were cultured in a manner similar to that used for the CF33 cells.

Cell proliferation analysis. To evaluate the effect of COX-2 selective inhibitors on cell proliferation, the untreated and treated cells were subjected to a WST- 8 assay using Cell Counting Kit-8 (Dojindo Laboratories, Kumamoto, Japan). The CF33 cells were seeded at a density of $1 \times 10^{3}$ cells/well into 96-well plates (BD Falcon, Tokyo, Japan). At each timepoint (days 0-4), $10 \mu \mathrm{l}$ of CCK-8 reagent was added. After a 2-h incubation, the absorbance was measured at $450 \mathrm{~nm}$ using a Benchmark Plus microplate reader (Bio-Rad Laboratories, Tokyo, Japan). In these experiments, 5 replicate wells were used for each time-point.

Cell cycle and apoptosis analyses. CF33 cells were seeded at a density of $2.5 \times 10^{5}$ cells/100-mm dish (BD Falcon). After the cells were treated, they were harvested and washed with PBS, resuspended in $70 \%$ ethanol in PBS, and incubated at $-30^{\circ} \mathrm{C}$ overnight. Prior to the analysis, the cells were mixed and incubated in the dark for $15 \mathrm{~min}$ in PI/RNase staining buffer (BD Pharmingen, San Jose, CA, USA). The suspension was then filtered through a $5-\mathrm{ml}$ polystyrene round-bottom tube with a cell-strainer cap (Becton-Dickinson, Franklin Lakes, NJ, USA) and analyzed using FACSCanto (Becton Dickinson) and FlowJo 7 (Tree Star, Ashland, OR, USA).

Trypan blue exclusion assay. Cells were seeded at a density of $1 \times 10^{5}$ cells in $60-\mathrm{mm}$ dishes at $24 \mathrm{~h}$ before DMSO or COX-2 inhibitor treatment. The cells were incubated in the presence of meloxicam $(100 \mu \mathrm{M})$, etodolac $(100 \mu \mathrm{M})$ and celecoxib $(100 \mu \mathrm{M})$ for $24 \mathrm{~h}$. The cells were washed with PBS, trypsinized and resuspended in PBS. The suspended cells were incubated with $0.4 \%(\mathrm{w} / \mathrm{v})$ trypan blue solution (Wako Pure Chemical Industries) for $1 \mathrm{~min}$ at room temperature, and the number of stained cells was counted.

Real-time RT-PCR. Total RNA was extracted from cells using the TRIzol reagent (Invitrogen, Carlsbad, CA, USA) according to the manufacturer's instructions and our previously described methods (12-14). cDNA was synthesized using a PrimeScript ${ }^{\mathrm{TM}}$ RT reagent kit (Perfect Real-Time) (Takara Bio, Shiga, Japan) according to the manufacturer's protocols. Real-time PCR was performed using SYBR Premix Ex Taq ${ }^{\mathrm{TM}}$ II (Tli RNaseH Plus) (Takara Bio) and the ABI Prism 7500 Real-Time PCR system (Applied Biosystems, Foster City, CA, USA) under the following conditions: $95^{\circ} \mathrm{C}$ for $30 \mathrm{sec}$ and 40 cycles each of $95^{\circ} \mathrm{C}$ for $5 \mathrm{sec}$ and $60^{\circ} \mathrm{C}$ for $34 \mathrm{sec}$. Glyceraldehyde-3phosphate dehydrogenase (GAPDH) expression was used as an internal control. The primer sequences are shown in Table I. The primers for BAX and Bcl-2 were purchased from Takara Bio, and the primer for GAPDH was obtained from Operon Biotechnologies (Tokyo, Japan). All the samples were amplified in triplicate in each experiment. The relative levels of mRNA were calculated using the $\Delta \Delta \mathrm{Ct}$ method.

Western blotting. Whole cell lysates were harvested using RIPA buffer containing protease inhibitors. The total cell lysate extraction was performed as previously described (14). The protein concentration of the cell lysates was measured using a Pierce ${ }^{\circledR}$ BCA Protein Assay kit (Pierce, Rockford, IL, USA). Then, the cell lysates (15-20 $\mu \mathrm{g}$ ) were boiled for $5 \mathrm{~min}$ in Laemmli sample buffer before being subjected to electrophoresis on $12 \%$ gel (BAX) and 10\% (COX-2) SDS-PAGE gels and were subsequently transferred to PVDF membranes (Bio$\mathrm{Rad})$. The primary antibody against BAX was purchased from Cell Signaling Technology (Tokyo, Japan), the anti-COX-2 antibody was obtained from Abcam (Tokyo, Japan), and the anti-actin antibody was purchased from Sigma Aldrich. The immune complex was detected using WesternBright Sirius Western Blotting Detection kit (Advansta, Menlo Park, CA, USA) according to the manufacturer's instructions.

Quantification of the caspase-3 and caspase-7 activities. To determine the activity of caspase- 3 and caspase-7, we analyzed the treated and untreated cells using Caspase-Glo ${ }^{\circledR} 3 / 7$ assays (Promega, Tokyo, Japan) according to the manufacturer's instructions. The fluorescence was measured using an ARVO $^{\text {TM }} 1420$ Multilabel Counter (Perkin-Elmer, Tokyo, Japan). 
Table I. Primer sequences for real-time RT-PCR.

\begin{tabular}{lll}
\hline Gene & \multicolumn{1}{c}{ Forward $\left(5^{\prime}-3 '\right)$} & \multicolumn{1}{c}{ Reverse $\left(5^{\prime}-3^{\prime}\right)$} \\
\hline GAPDH & ATTCTATCCACGGCAAATCC & GGACTCCACAACATACTCAG \\
BAX & CGCATCGGAGATGAACTGGA & ACCAGTTTGCTGGCAAAGTAGAAG \\
Bcl-2 & TGAACCGGCATCTGCACAC & GAGCAGCGCCTTCAGAGACA \\
\hline
\end{tabular}

A

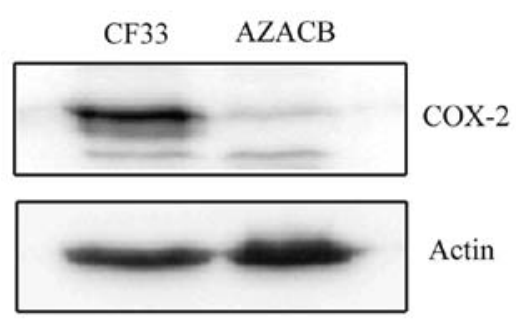

B

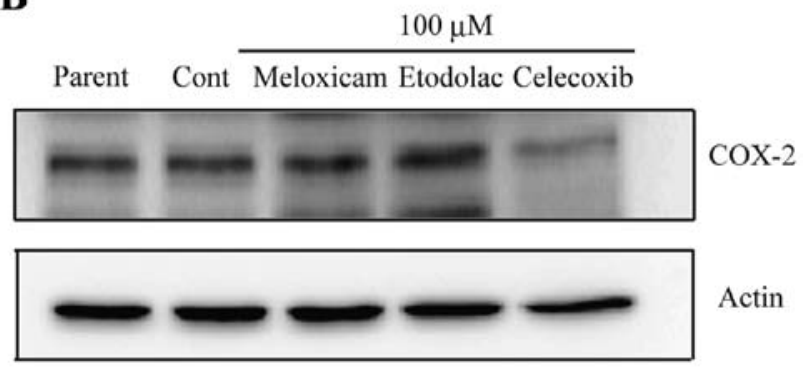

Figure 1. Celecoxib-induced downregulation of COX-2 protein expression in CF33 cells. (A) Protein level of COX-2 was analyzed by western blotting in CF33 cells and AZACB cells. (B) Western blot analysis of COX-2 expression in CF33 cells treated with selective COX-2 inhibitors (100 $\mu$ M; meloxicam, etodolac and celecoxib) for $24 \mathrm{~h}$. As a control, CF33 cells were treated with DMSO at a final concentration of $0.1 \%$. The term 'parent cells' was used to refer to non-treated cells.

Identifying the stages of apoptosis. The stages of apoptosis were analyzed using the ApoAlert ${ }^{\circledR}$ Annexin V-FITC Apoptosis kit (Clontech Laboratories, Inc., Palo Alto, CA, USA) according to the manufacturer's instructions. The cells were seeded at a density of $2.5 \times 10^{5}$ cells/well in 100-mm dishes (BD Falcon). Both adherent and non-adherent cells were harvested (trypsin, $0.25 \%$ ) and centrifuged. After washing and then resuspending the cell pellets in binding buffer, the cells were incubated with Annexin V-FITC and PI for $15 \mathrm{~min}$ in the dark at room temperature. The samples were analyzed using FACSCanto and FlowJo 7.

Statistical analysis. To determine significant differences between the selective COX-2 inhibitor-treated cells and the control cells, statistical analysis was performed using paired two-tailed Student's t-test. $\mathrm{P}<0.05$ was considered to indicate a statistically significant difference.

\section{Results}

Celecoxib reduces COX-2 expression in CF33 cells. Immunohistochemical analysis has shown a tendency of an increase in COX-2 expression in canine mammary tumors compared to benign tumors (9). Therefore, we examined and compared COX-2 protein expression in CF33 and AZACB cells. The CF33 cells exhibited higher COX-2 protein levels than the AZACB cells (Fig. 1A). This result may indicate that COX-2 contributes to maintaining the malignant phenotype of $\mathrm{CF} 33$ cells. To determine the antitumor effect of selective COX-2 inhibitors in canine mammary tumor cells, we used CF33 cell lines that highly expressed COX-2. To clarify whether selective COX-2 inhibitors affect COX-2 expression patterns, we compared COX-2 protein levels in selective COX-2 inhibitor- treated CF33 cells. COX-2 protein expression levels were markedly downregulated after $24 \mathrm{~h}$ of celecoxib treatment $(100 \mu \mathrm{M})$ (Fig. 1B). However, meloxicam or etodolac treatment did not alter COX-2 expression (Fig. 1B). This finding may suggest that celecoxib effectively inhibits the function of COX-2 in canine mammary tumor cells. Similar results have also been observed in human cancer cell lines (15). Celecoxib-induced COX-2 downregulation is thought to occur at the transcriptional level due to the inhibition of $N F-\kappa B$ activity (16).

Selective COX-2 inhibitors, especially celecoxib, markedly inhibit CF33 cell proliferation via a decrease in the percentage of $S$-phase cells and induction of G0/G1 arrest. A number of studies have provided conclusive evidence that selective COX-2 inhibitors possess potential chemopreventative and chemotherapeutic activity in human breast cancer patients. To analyze the effect of selective COX-2 inhibitors on CF33 cell proliferation, we utilized a WST- 8 assay at $0,1,2,3$ and 4 days following the addition of each selective COX-2 inhibitor (meloxicam, etodolac and celecoxib) (Fig. 2). The number of parent and control cells increased steadily and nearly equally for 4 days after plating. However, the rate of CF33 cell proliferation was suppressed in a dose-dependent manner following meloxicam, etodolac and celecoxib treatment (Fig. 2A). Notably, CF33 cell proliferation was completely blocked from days 1-4 after the celecoxib (100 $\mu \mathrm{M})$ treatment (Fig. 2C). The cells treated with celecoxib $(100 \mu \mathrm{M})$ exhibited a marked decrease in the percentage of S-phase cells and an increase in G0/G1 arrest (Fig. 3C). Moreover, the celecoxib (100 $\mu \mathrm{M})$-treated cells exhibited a marked alteration in the percentage of S-phase and G0/G1-phase cells. 

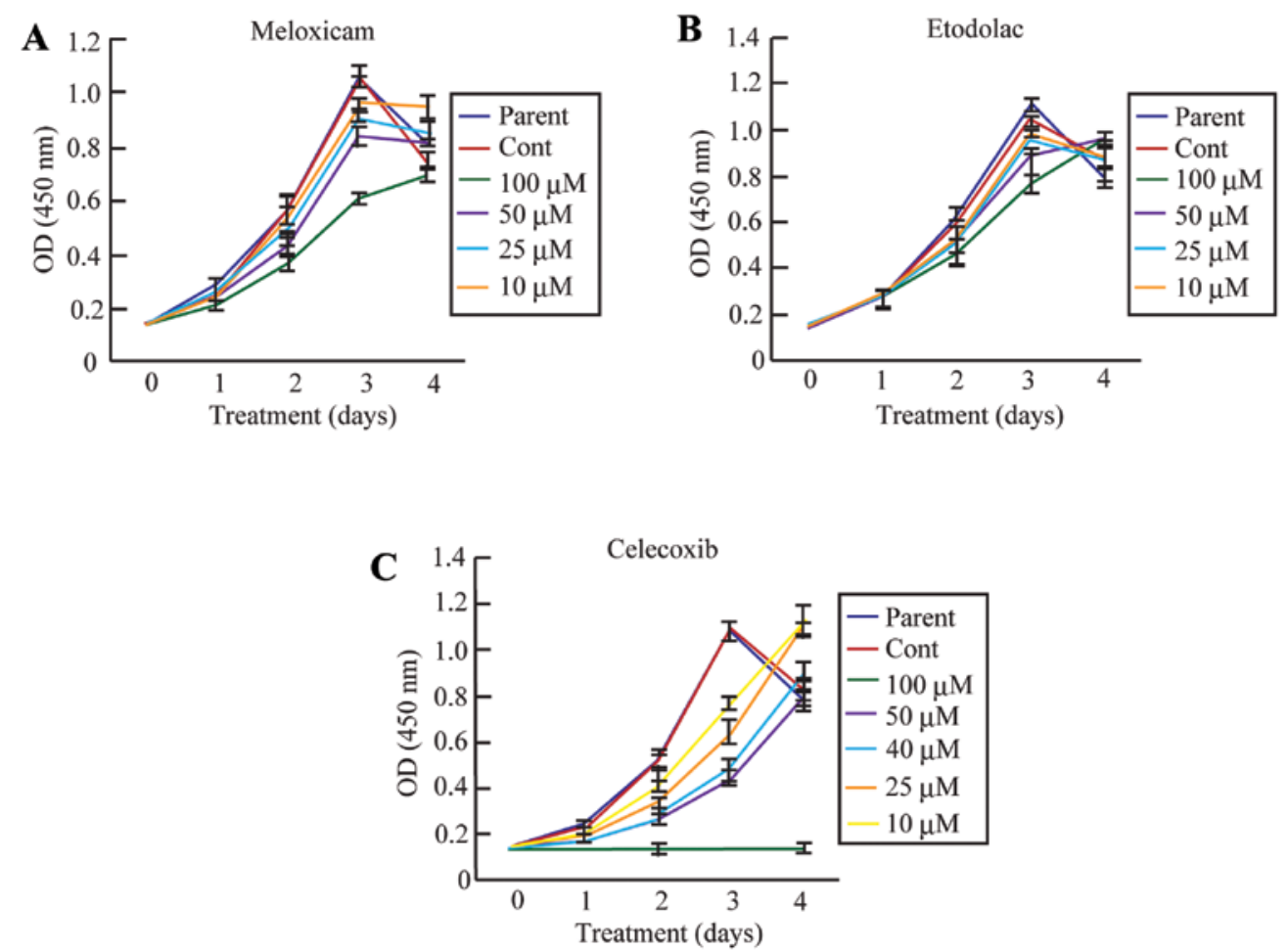

Figure 2. Selective COX-2 inhibitors, especially celecoxib, markedly inhibit CF33 cell proliferation in a dose-dependent manner. The effects of selective COX-2 inhibitors on cell proliferation were analyzed using a WST- 8 assay from day 0 to day 4 of culture. The data are shown as the mean \pm SD ( $n=5$ ). (A) The effects of meloxicam (A), etodolac (B) and celecoxib (C) on CF33 cell proliferation.

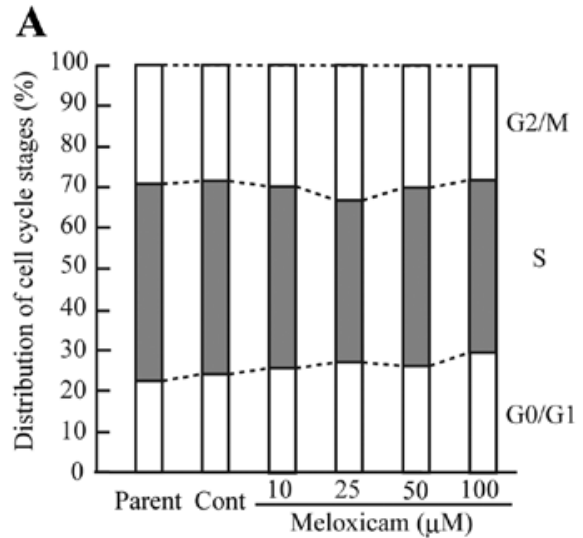

C

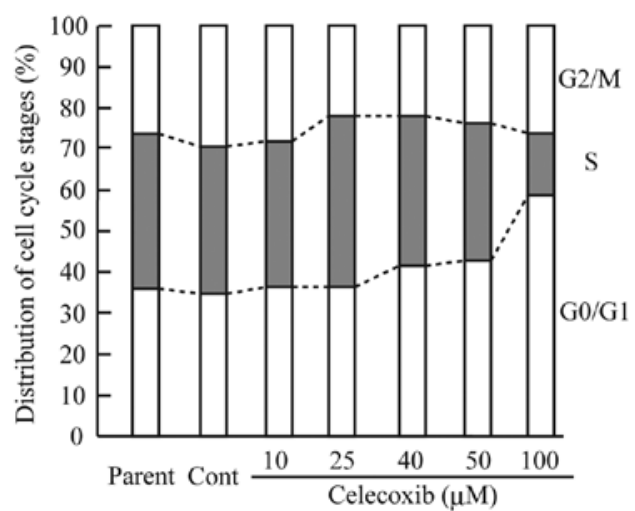

B

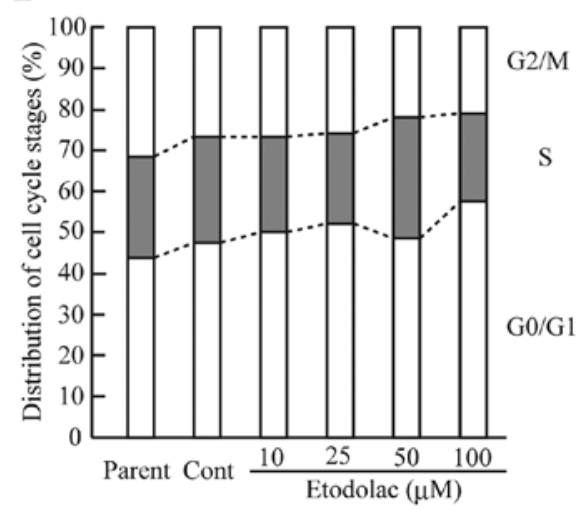

D

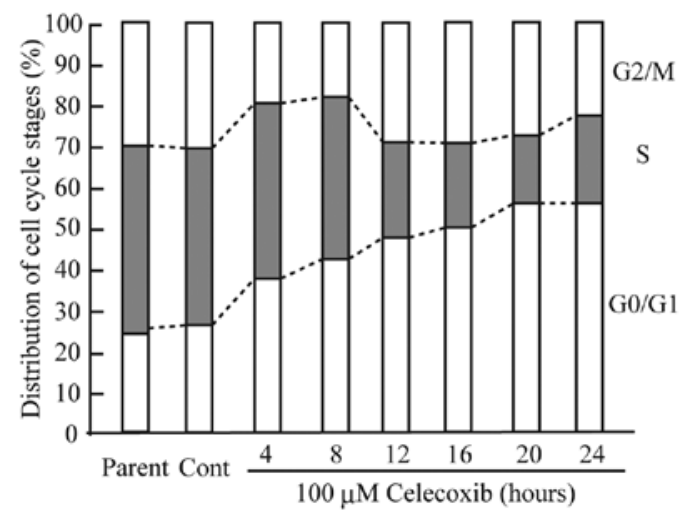

Figure 3. Celecoxib treatment decreases cells in the S phase and increases cells in G0/G1 arrest. To analyze the effects of selective COX-2 inhibitors on the distribution of each cell cycle stage, treated and untreated cells were assessed by FACS analysis (A-D). (A-C) The percentage of cells distributed in each cell cycle stage after treatment with meloxicam (A), etodolac (B) and celecoxib (C). (D) The distribution of each cell-cycle stage in CF33 cells treated with $100 \mu \mathrm{M}$ celecoxib for 4, 8, 12, 16, 20 and $24 \mathrm{~h}$. These data were obtained by analyzing 20,000 cells in each experiment. 
A

\begin{tabular}{|c|c|c|}
\hline & $\begin{array}{c}\text { Number of total cells } \\
\left(\times 10^{4}\right)\end{array}$ & $\begin{array}{c}\text { Number of dead cells } \\
\left(\times 10^{4}\right)\end{array}$ \\
\hline Parent & $109.3 \pm 9.6$ & 0 \\
\hline Control & $116.7 \pm 12.3$ & 0 \\
\hline $\begin{array}{c}\text { Meloxicam } \\
(100 \mu \mathrm{M})\end{array}$ & $91.3 \pm 12.9$ & 0 \\
\hline $\begin{array}{c}\text { Etodolac } \\
(100 \mu \mathrm{M})\end{array}$ & $79.7 \pm 13.2$ & $0.3 \pm 0.6$ \\
\hline $\begin{array}{c}\text { Celecoxib } \\
(100 \mu \mathrm{M})\end{array}$ & $28.0 \pm 5.6$ & $0.8 \pm 0.6$ \\
\hline
\end{tabular}

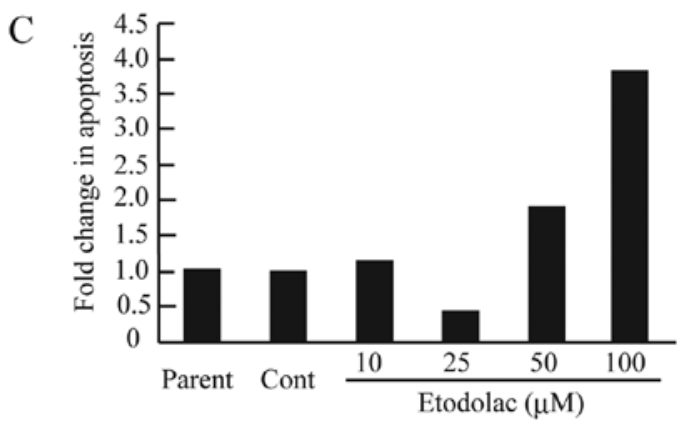

B

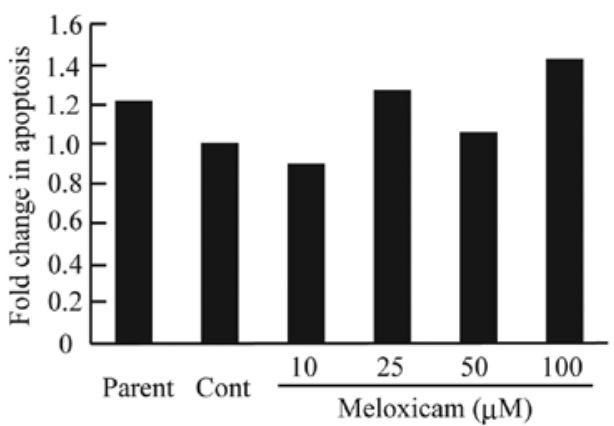

$\mathrm{D}$

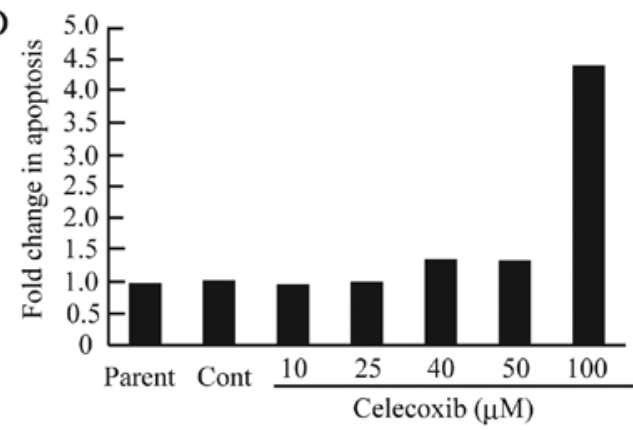

Figure 4. Etodolac- and celecoxib-induced apoptosis in CF33 cells. To analyze the effect of selective COX-2 inhibitors on the induction of apoptosis in CF33 cells, we utilized a trypan blue exclusion assay and FACS analysis. (A) The number of dead cells identified using the trypan blue exclusion assay. (B-D) FACS analysis of apoptotic cells treated with the vehicle (Control) or different concentrations of selective COX-2 inhibitors for 24 h. The data from 20,000 cells were analyzed using FlowJo 7.

Meloxicam (100 $\mu \mathrm{M})$ and etodolac $(100 \mu \mathrm{M})$ treatment also strongly inhibited CF33 cell proliferation (Fig. 2A and B). However, G0/G1 arrest was slightly induced in the CF33 cells treated with a higher dose of meloxicam and etodolac (Fig. 3A and B). These data suggest that celecoxib strongly induced the inhibition of cell proliferation in canine mammary tumor cells. Furthermore, these results indicate that selective COX-2 inhibitors are capable of inhibiting the cell proliferation of canine mammary tumor cells, similar to the inhibition observed in human breast cancer cells from previous studies.

Celecoxib is a more powerful apoptosis inducer than etodolac or meloxicam in canine mammary tumor cells. Selective COX-2 inhibitors markedly suppressed the proliferation of CF33 cells in our experiments. To determine whether selective COX-2 inhibitors induced apoptosis in the CF33 cells, the cells were exposed to meloxicam, etodolac or celecoxib for $24 \mathrm{~h}$ and were then analyzed using a trypan blue exclusion assay. In the meloxicam-treated cells, dead or apoptotic cells were not observed (Fig. 4A and B). However, treatment with etodolac $(100 \mu \mathrm{M})$ or celecoxib $(100 \mu \mathrm{M})$ increased the number of dead cells $\left[(0.3 \pm 0.6) \times 10^{4}\right.$ and $(0.8 \pm 0.6) \times 10^{4}$, respectively] (Fig. 4A). To determine whether the etodolac- or celecoxibinduced CF33 cell death was a result of apoptosis, the cells were stained with PI and analyzed using FACS. Apoptosis was induced more frequently in the CF33 cells treated with a high dose of etodolac or celecoxib (Fig. 4C and D). Specifically, the treatment with $100 \mu \mathrm{M}$ of etodolac or celecoxib elevated the proportion of apoptotic cells by $\sim 3.7$ - and 4.6-fold, respectively (Fig. 4C and D). The imbalance between pro-apoptotic molecules (BAX and BAK) and anti-apoptotic molecules
(Bcl-2 and $\mathrm{Bcl}-\mathrm{X}_{\mathrm{L}}$ ) induces apoptosis mediated by the stimulation of mitochondrial outer membrane permeabilization (MOMP) (17). To further clarify the effect of selective COX-2 inhibitors on apoptosis, we measured $B A X$ and $B c l-2$ mRNA and BAX protein expression levels using real-time RT-PCR and western blotting. Celecoxib treatment caused a marked increase in $B A X$ mRNA expression and a decrease in $B c l-2$ mRNA expression compared with the control cells (Fig. 5A and $\mathrm{B})$. In addition, we observed that celecoxib treatment caused a significant increase in BAX protein levels compared with that in the other cells (Fig. 5C). However, the $\mathrm{Bcl}-2 \mathrm{mRNA}$ levels were also downregulated in the CF33 cells treated with the other selective COX-2 inhibitors (Fig. 5B). The activation of the effectors caspase- 3 and caspase-7 following the activation of the initiator caspase- 9 or caspase- 8 is important for the induction of apoptosis (18). To further clarify the effect of selective COX-2 inhibitors on apoptosis, we analyzed the degree of caspase-3/7 activity. Only the celecoxib-treated cells induced the activation of caspase-3 and caspase-7 (Fig. 5D). To further confirm the induction of apoptosis in the CF33 cells treated with celecoxib, we assessed apoptosis using Annexin V and PI staining. Our results demonstrated that celecoxib $(100 \mu \mathrm{M})$ treatment decreased the $\mathrm{CF} 33$ cell survival rate and increased the percentages of both early and late apoptotic CF33 cells (Fig. 6). These results may indicate that celecoxib induces strong cell proliferation inhibition in canine mammary tumor cells by activating the intrinsic apoptosis pathway. Our data indicate that celecoxib and etodolac may induce apoptosis in canine mammary tumor cells. However, meloxicam did not induce an apoptotic effect in canine mammary tumor cells in the present study. 
A

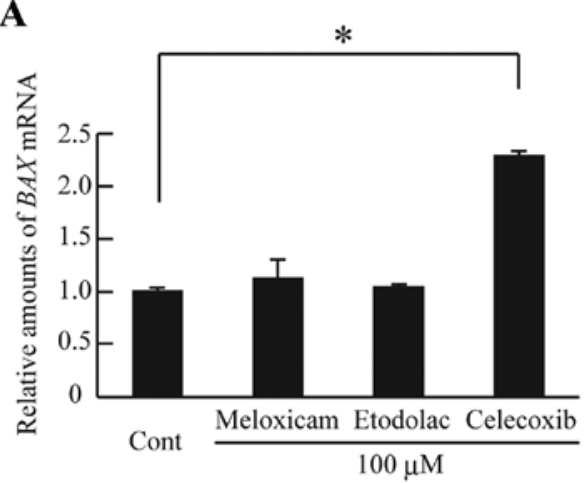

C

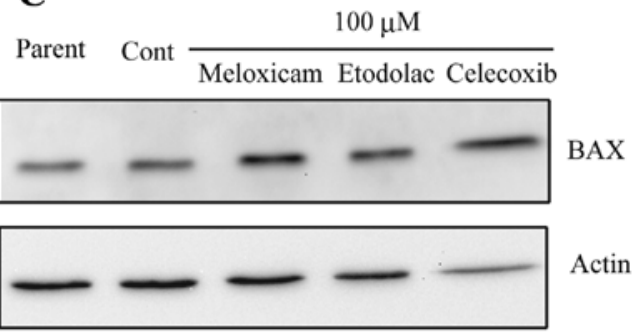

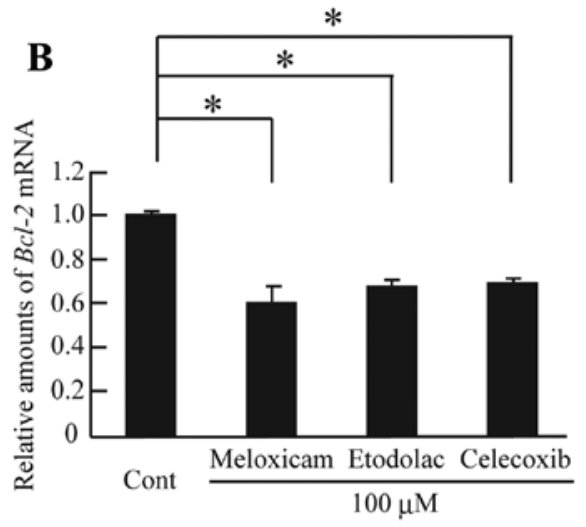

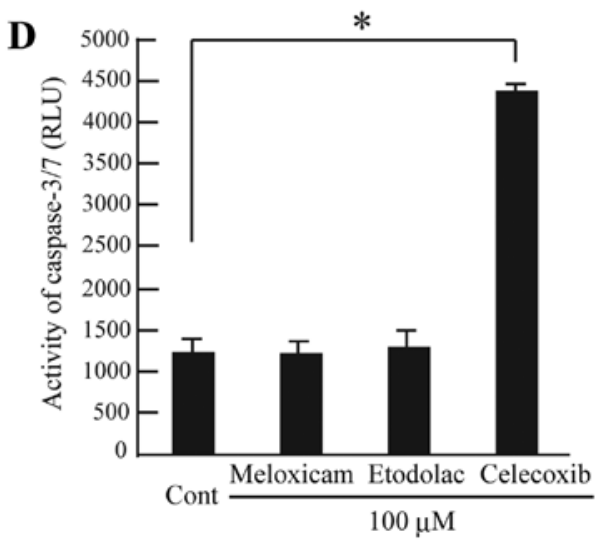

Figure 5. Celecoxib induces activation of the intrinsic apoptosis pathway in CF33 cells. To determine the effect of selective COX-2 inhibitors on apoptosisrelated molecules, we measured BAX and Bcl-2 expression and caspase-3/7 activities. (A) BAX and (B) Bcl-2 mRNA expression in CF33 cells treated with selective COX-2 inhibitors for $24 \mathrm{~h}$ was measured using real-time RT-PCR analysis. The data represent the mean \pm SD. This analysis was performed in triplicate. (C) Western blotting for BAX in CF33 cells treated with $100 \mu \mathrm{M}$ selective COX-2 inhibitors for $24 \mathrm{~h}$. (D) Luminescent assay for caspase-3/7 activity in CF33 cells treated with $100 \mu \mathrm{M}$ selective COX-2 inhibitors for $24 \mathrm{~h}$. The data represent the mean $\pm \mathrm{SD}$. This analysis was performed in pentad.
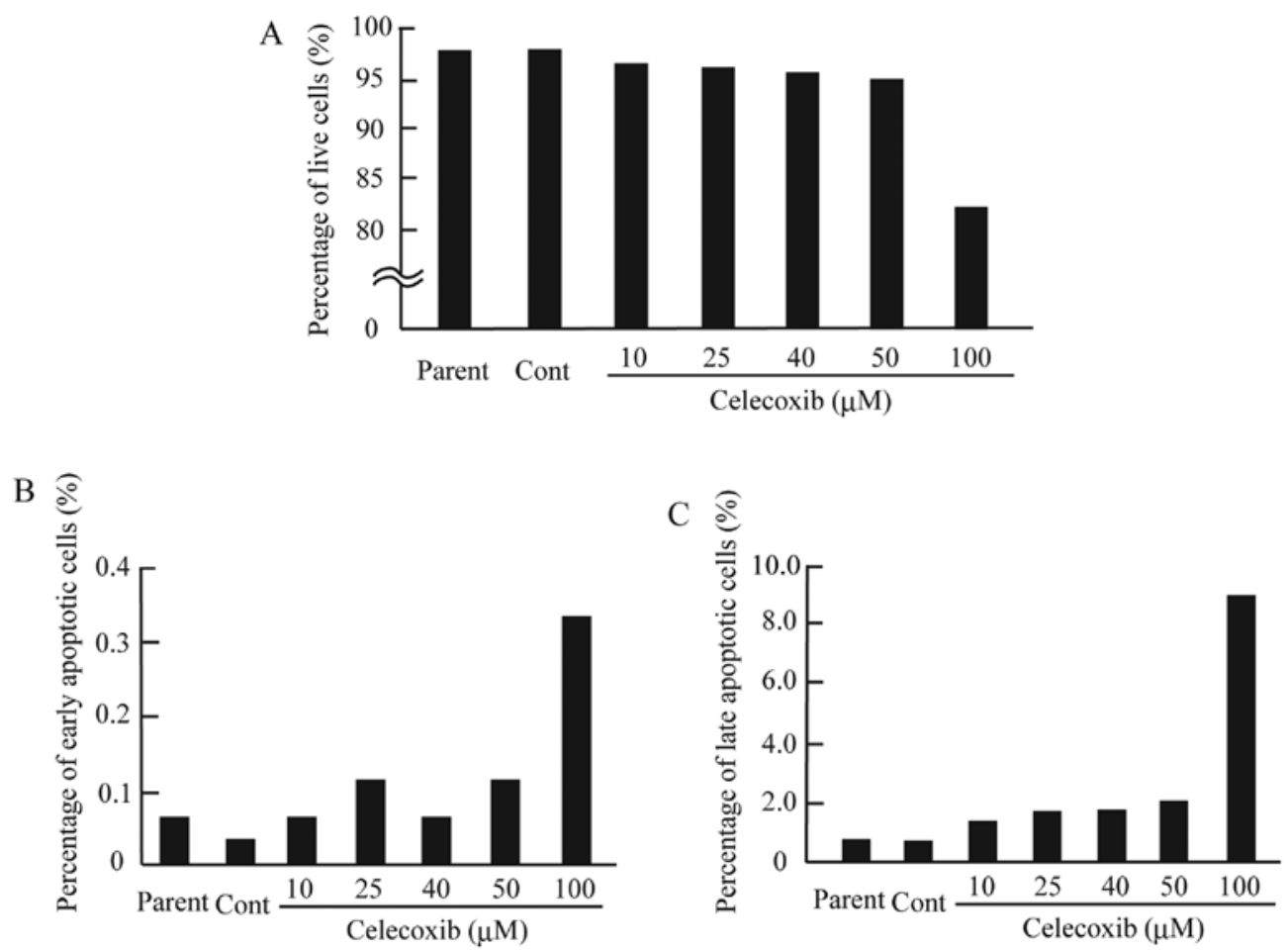

Figure 6. Celecoxib treatment decreases CF33 cell survival rate and increases both early and late CF33 apoptotic cells. To further analyze the apoptotic effect of celecoxib on CF33 cells, treated and untreated cells were analyzed using Annexin V-FITC and PI double staining. (A) The percentage of live cells (Annexin-/PI-). (B) The percentage of early apoptotic cells (Annexin+/PI-). (C) The percentage of late apoptotic cells (Annexin+/PI+). Data from 20,000 cells were analyzed using FlowJo 7. 


\section{Discussion}

Recent studies have demonstrated that NSAIDs, especially selective COX-2 inhibitors, are useful for chemotherapy or chemoprevention of various human cancers via the induction of apoptosis and the inhibition of cell growth $(19,20)$. However, the mechanism of action of selective COX-2 inhibitors against canine mammary tumors remains unclear; therefore, the aim of the present study was to elucidate the mechanism of action of selective COX-2 inhibitors against canine mammary tumor cells. Our experiments revealed that selective COX-2 inhibitors inhibited the proliferation of canine CF33 mammary tumor cells. Specifically, our findings demonstrated that celecoxib induced CF33 apoptosis more robustly than meloxicam and etodolac treatment in CF33 cells. Furthermore, our findings indicated that celecoxib-induced apoptosis is mediated by the activation of the intrinsic apoptosis pathway. These results suggest that celecoxib has a strong antitumor potency in canine mammary tumor cells.

Compared with the findings for normal tissue, COX-2 expression has been observed to be elevated in various human premalignant and malignant tumors, such as colorectal, breast and lung cancers (21). Similarly, in canines, COX-2 is overexpressed in breast and prostate cancers (22). Compared with the findings for canine mammary adenoma tumors, COX-2 expression is increased in cases of canine mammary adenocarcinoma with malignant phenotypes (9). Furthermore, metastatic lesions of malignant mammary tumor tissue exhibited intense immunohistochemical COX-2 staining (23). These previous reports indicate that COX-2 plays an important role in the initiation and promotion of mammary tumors and the maintenance of the malignant phenotype of canine mammary tumors. The present results demonstrated that celecoxib induced apoptosis, which was associated with a downregulation of COX-2 protein expression levels in canine mammary tumor cells. Therefore, this finding supports the hypothesis that celecoxib is a useful therapeutic agent for COX-2-positive canine mammary tumors.

In vertebrate cells, caspase-dependent apoptosis is divided into two pathways, the intrinsic and extrinsic pathways, which are induced by different initiation cascades (24-26). The intrinsic apoptosis pathway (also known as the mitochondrial pathway or the stress pathway) is initiated by a variety of chemical or physical stressors, such as DNA damage by UV irradiation and endoplasmic reticulum stress (27). However, the extrinsic apoptosis pathway is initiated via the interaction of a death receptor (FAS and TNF- $\alpha$ ) with its ligand (FAS-L and TNF- $\alpha$ L) $(25,26)$. Whether the mechanism of celecoxibinduced apoptosis occurs through the intrinsic pathway or the extrinsic pathway remains controversial. Some studies have proposed that celecoxib initiates the extrinsic apoptosis pathway mediated by activating caspase- 8 via the induction of DR5 (TRAIL receptor 2) expression (28). However, several studies have reported that celecoxib induces apoptosis by activating the intrinsic apoptosis pathway (29,30). Our observation indicates that celecoxib activated the intrinsic apoptosis pathway in canine mammary tumor cells by activating caspase-3/7 via the downregulation of $\mathrm{Bcl}-2$ and the upregulation of BAX. Furthermore, $\mathrm{PGE}_{2}$ treatment has been shown to inhibit the induction of apoptosis in human colon cancer cells with selective COX-2 inhibitor-mediated Bcl-2 upregulation (31). The present study also suggests that celecoxib directly affects the expression levels of Bcl-2 in canine mammary tumor cells.

In patients with a history of colorectal neoplasms, the chronic administration of celecoxib increases the risk for serious cardiovascular side-effects compared to that for the placebo group (32), and other coxib-class drugs can produce similar side-effects. This phenomenon may be explained by an imbalance between prostacyclin $\left(\mathrm{PGI}_{2}\right)$ and thromboxane $\mathrm{A}_{2}$ $\left(\mathrm{TXA}_{2}\right)$, which is caused by the inhibition of COX-2-derived $\mathrm{PGI}_{2}$ in endothelial cells without the inhibition of COX-1dependent $\mathrm{TXA}_{2}$ production in platelets (33). To determine the inhibition of COX-2 activity by selective COX-2 inhibitors, we analyzed the alteration of COX-2 activity and $\mathrm{PGE}_{2}$ production of CF33 cells. However, we did not observe any changes in $\mathrm{CF} 33 \mathrm{COX}-2$ activity and $\mathrm{PGE}_{2}$ production after treatment with selective COX-2 inhibitors (meloxicam, etodolac and celecoxib) (data not shown). Celecoxib analogs have previously been shown to exhibit an antitumor effect through a COX-2independent mechanism (34). Our results raise the possibility of selective COX-2 inhibitor-mediated CF33 cell proliferation inhibition via a COX-2-independent manner. Furthermore, since COX-2 activity was not inhibited, the chronic administration of selective COX-2 inhibitors in canines may not cause the severe cardiovascular side-effects observed in humans.

In conclusion, our results indicate that selective COX-2 inhibitors may be a viable option for chemotherapy or chemoprevention against canine mammary tumors. In canine mammary tumors, celecoxib would function as a chemotherapeutic agent by inducing apoptosis. Furthermore, our findings also provide additional evidence that $\mathrm{COX}-2$ is a suitable for therapeutic and preventative target in canine mammary tumors. In the future, it may be possible to use a combination of other antitumor drugs and selective COX-2 inhibitors as a treatment protocol for canine mammary tumors.

\section{Acknowledgements}

We thank H. Sugiya and T. Narita for the critical discussions. The present study was supported in part by a Grant-in-Aid from Nihon University (to T.S.) and funds from the Laboratory of Veterinary Pharmacology, Nihon University College of Bioresource Sciences.

\section{References}

1. Chandrasekharan NV, Dai H, Roos KL, Evanson NK, Tomsik J, Elton TS and Simmons DL: COX-3, a cyclooxygenase-1 variant inhibited by acetaminophen and other analgesic/antipyretic drugs: cloning, structure, and expression. Proc Natl Acad Sci USA 99: 13926-13931, 2002.

2. Hanahan D and Weinberg RA: Hallmarks of cancer: the next generation. Cell 144: 646-674, 2011.

3. Dennis LK, Lynch CF and Torner JC: Epidemiologic association between prostatitis and prostate cancer. Urology 60: 78-83, 2002.

4. Howe LR: Inflammation and breast cancer. Cyclooxygenase/ prostaglandin signaling and breast cancer. Breast Cancer Res 9: $210,2007$.

5. Coussens LM and Werb Z: Inflammation and cancer. Nature 420: 860-867, 2002.

6. Liao X, Lochhead P, Nishihara R, et al: Aspirin use, tumor PIK3CA mutation, and colorectal-cancer survival. N Engl J Med 367: 1596-1606, 2012. 
7. Holmes MD, Chen WY, Li L, Hertzmark E, Spiegelman D and Hankinson SE: Aspirin intake and survival after breast cancer. J Clin Oncol 28: 1467-1472, 2010.

8. Stratmann N, Failing K, Richter A and Wehrend A: Mammary tumor recurrence in bitches after regional mastectomy. Vet Surg 37: 82-86, 2008

9. Doré M, Lanthier I and Sirois J: Cyclooxygenase-2 expression in canine mammary tumors. Vet Pathol 40: 207-212, 2003.

10. Queiroga FL, Alves A, Pires I and Lopes C: Expression of Cox-1 and Cox-2 in canine mammary tumours. J Comp Pathol 136 : 177-185, 2007.

11. Klopfleisch R, von Euler H, Sarli G, Pinho SS, Gartner F and Gruber AD: Molecular carcinogenesis of canine mammary tumors: news from an old disease. Vet Pathol 48: 98-116, 2011.

12. Saito T, Tamura D, Nakamura T, et al: 4-methylumbelliferone leads to growth arrest and apoptosis in canine mammary tumor cells. Oncol Rep 29: 335-342, 2013.

13. Saito T, Dai T and Asano R: The hyaluronan synthesis inhibitor 4-methylumbelliferone exhibits antitumor effects against mesenchymal-like canine mammary tumor cells. Oncol Lett 5: 1068-1074, 2013

14. Saito T, Kawana H, Azuma K, Toyoda A, Fujita H, Kitagawa M and Harigaya K: Fragmented hyaluronan is an autocrine chemokinetic motility factor supported by the HAS2-HYAL2/CD44 system on the plasma membrane. Int J Oncol 39: 1311-1320, 2011

15. Zhang GS, Liu DS, Dai CW and Li RJ: Antitumor effects of celecoxib on K562 leukemia cells are mediated by cell-cycle arrest, caspase- 3 activation, and downregulation of Cox- 2 expression and are synergistic with hydroxyurea or imatinib. Am J Hematol 81: 242-255, 2006.

16. Shishodia S, Koul D and Aggarwal BB: Cyclooxygenase (COX)-2 inhibitor celecoxib abrogates TNF-induced $\mathrm{NF}-\kappa \mathrm{B}$ activation through inhibition of activation of I $\mathrm{B} \alpha \alpha$ kinase and Akt in human non-small cell lung carcinoma: correlation with suppression of COX-2 synthesis. J Immunol 173: 2011-2022, 2004.

17. Chipuk JE and Green DR: How do BCL-2 proteins induce mitochondrial outer membrane permeabilization? Trends Cell Biol 18: 157-164, 2008

18. Li P, Nijhawan D, Budihardjo I, Srinivasula SM, Ahmad M, Alnemri ES and Wang X: Cytochrome c and dATP-dependent formation of Apaf-1/caspase-9 complex initiates an apoptotic protease cascade. Cell 91: 479-489, 1997.

19. William WN Jr, Heymach JV, Kim ES and Lippman SM Molecular targets for cancer chemoprevention. Nat Rev Drug Discov 8: 213-225, 2009.
20. Harris RE: Cyclooxygenase-2 (COX-2) blockade in the chemoprevention of cancers of the colon, breast, prostate, and lung. Inflammopharmacology 17: 55-67, 2009.

21. Dannenberg AJ and Subbaramaiah K: Targeting cyclooxygenase-2 in human neoplasia: rationale and promise. Cancer Cell 4: 431-436, 2003.

22. Doré M: Cyclooxygenase-2 expression in animal cancers. Vet Pathol 48: 254-265, 2011.

23. Dias Pereira P, Lopes CC, Matos AJ, Santos M, Gärtner F, Medeiros R and Lopes C: COX-2 expression in canine normal and neoplastic mammary gland. J Comp Pathol 140: 247-253, 2009.

24. Hengartner MO: The biochemistry of apoptosis. Nature 407: 770-776, 2000.

25. Ola MS, Nawaz M and Ahsan H: Role of Bcl-2 family proteins and caspases in the regulation of apoptosis. Mol Cell Biochem 351: 41-58, 2011.

26. Igney FH and Krammer PH: Death and anti-death: tumour resistance to apoptosis. Nat Rev Cancer 2: 277-288, 2002.

27. Tait SW and Green DR: Mitochondria and cell death: outer membrane permeabilization and beyond. Nat Rev Mol Cell Biol 11: 621-632, 2010.

28. Liu X, Yue P, Zhou Z, Khuri FR and Sun SY: Death receptor regulation and celecoxib-induced apoptosis in human lung cancer cells. J Natl Cancer Inst 96: 1769-1780, 2004.

29. Jendrossek V, Handrick R and Belka C: Celecoxib activates a novel mitochondrial apoptosis signaling pathway. FASEB J 17: $1547-1549,2003$

30. Jendrossek V: Targeting apoptosis pathways by Celecoxib in cancer. Cancer Lett 332: 313-324, 2013.

31. Sheng H, Shao J, Morrow JD, Beauchamp RD and DuBois RN: Modulation of apoptosis and $\mathrm{Bcl}-2$ expression by prostaglandin $\mathrm{E}_{2}$ in human colon cancer cells. Cancer Res 58: 362-366, 1998.

32. Solomon SD, McMurray JJ, Pfeffer MA, et al: Cardiovascular risk associated with celecoxib in a clinical trial for colorectal adenoma prevention. N Engl J Med 352: 1071-1080, 2005.

33. Fitzgerald GA: Coxibs and cardiovascular disease. N Engl J Med 351: 1709-1711, 2004.

34. Schönthal AH, Chen TC, Hofman FM, Louie SG and Petasis NA: Celecoxib analogs that lack COX-2 inhibitory function: preclinical development of novel anticancer drugs. Expert Opin Investig Drugs 17: 197-208, 2008. 